\title{
Pitch and Yaw Attitude Control of a Rocket Engine Using Hybrid Fuzzy- PID Controller
}

\author{
R. Sumathi ${ }^{1, *}$ and M. Usha ${ }^{2}$ \\ ${ }^{1}$ Department of Electrical and Electronics Engineering, Pavai College of Technology, Namakkal, Tamil Nadu, India \\ ${ }^{2}$ Sona College of Technology, Salem, Tamil Nadu, India
}

\begin{abstract}
The rocket is the only vehicle that launches the spacecraft in the space. The orientation of the spacecraft in precise position is so crucial. But, the motion of the rocket can be influenced by internal and external disturbances. Furthermore, the rocket is a multi-input and multi-output nonlinear system whose dynamics are unstable and poorly understood. Hence, attitude control of the rocket is a big challenge with real time. To make the rocket stable against the influences, this paper has examined the control technology such as proportional integral derivative control using anti-windup mechanism and linear quadratic regulator theory based on the degree of freedom mathematical model. The transient behaviour of both the controller is not smooth and takes more time to settle in the defined location. Specific to the deficiencies of PID and LQR, the proportional integral derivative controller is combined with a fuzzy logic controller to overcome the defects of PID and LQR. In conclusion, this paper compares the performance analysis of fuzzy-PID controller with linear quadratic regulator and proportional integral derivative controller. The simulation results indicate that the hybrid fuzzy-PID controller has a remarkable improvement in terms of overshoot and settling time besides reducing steady state error. The proposed hybrid fuzzy-PID controller eliminates the overshoot completely and produces enormous stability to the rocket engine.
\end{abstract}

Keywords: Anti-windup, Attitude control, Fuzzy-PID controller, Linear quadratic regulator, MATLAB/Simulink, Proportional integral derivative controller, Rocket.

\section{INTRODUCTION}

Rocket attitude control has been an active research topic for quite sometime. The rocket produces pitch and yaw motions by gimballing the exhaust nozzle. In a gimbaled thrust system, the thrust direction can be controlled by controlling the nozzle gimbal angle so that the rocket can be launched in the exact route. The parameters which characterize the dynamics of the rocket are usually an approximation [1] and this leads to ambiguity in the empirical representation. Furthermore, a small perturbation kicks the rocket out of alignment and diminishes the stability of the rocket. Making the rocket stable requires some form of control system.

Until now, PID controllers are the most popular controller used in rocket control systems due to their simplicity and satisfactory performances. However, since the PID controller is developed based on the linear control theory, the controller gives inconsistent performances for different condition [2]. Also it requires a precise mathematical model. Nevertheless, the rocket is a non-linear and time varying system. The classical PID controller cannot attain the desired control results [3].

*Address correspondence to this author at the Department of Electrical and Electronics Engineering, Pavai College of Technology, Namakkal, Tamil Nadu, India; Tel: +91-8508867214; E-mail: elakkiyasumi@gmail.com
Many controllers on attitude controlling of satellites and rockets have been proposed but very few of these controllers can be applied to deal with many issues simultaneously.

Debabrata Roy, Ragupati Goswami, Sourish Sanyal and Amar Nath Sanyal designed proportional-derivative feedback controller for pitch attitude control of a rocket [4]. However, here the interference and non-linearities have not been taken into account. Le Zhang, Shaojie Bi and Hong Yang proposed Fuzzy-PID control algorithm for attitude control of the helicopter model flight [5]. Venkata Narayana, Vidya Sagar Bonu and Mallikarjuna Rao designed fuzzy logic based intelligent controller for a non-linear satellite's attitude control [6]. Beni Kusuma Atmaja and Endra Joelianto proposed MIMO PID robust integral back stepping method to improve the stability of the rocket in the presence of wind disturbance. But none of these methods eliminate the overshoot entirely.

To attain high attitude performance, this paper presents an intelligent control algorithm for a rigid missile using control torques supplied by thrusters about the pitch and yaw axis. This paper applies PID controller with anti-windup scheme and LQR for rocket attitude control. Also, the PID controller is combined with a fuzzy logic controller by blending mechanism and applied to control the rocket gimbal angle. The performances are compared. Both the PID controller and fuzzy logic controller have their own advantages. 


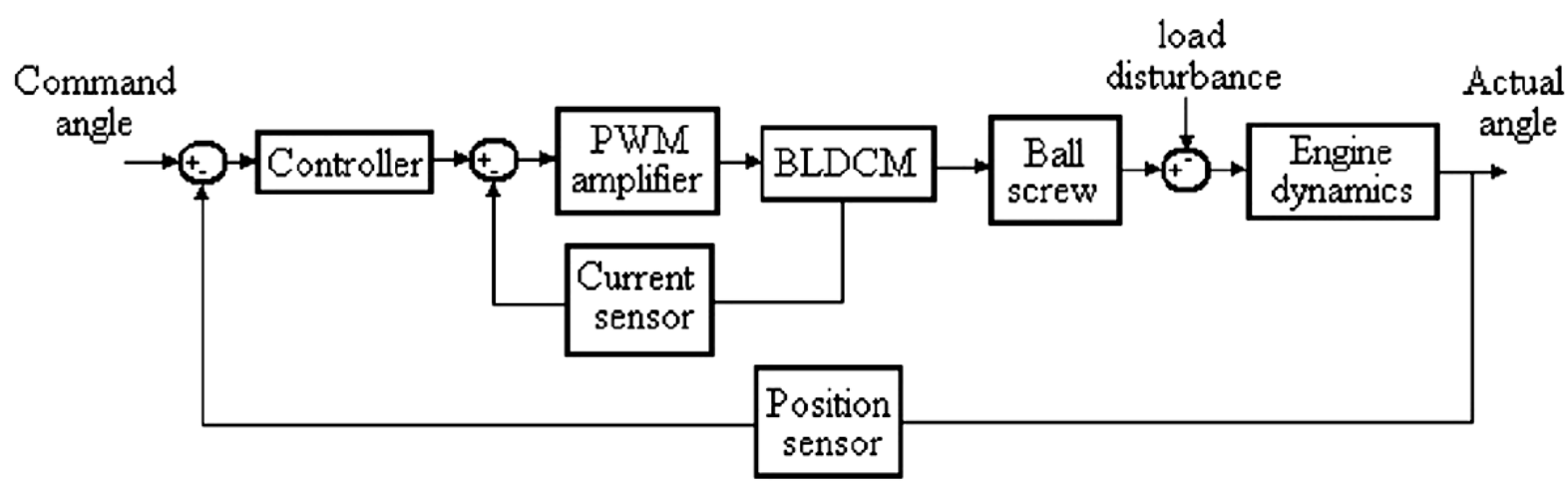

Fig. (1). Electro Mechanical Engine Gimbal Control System.

Based on their excellent qualities, the proposed hybrid fuzzy-PID controller produces less steady state error and zero overshoot which means that the stability of the rocket is magnificent.

\section{PROBLEM STATEMENT}

As mentioned above, the rocket gimbal angle control of pitch and yaw axis during electromechanical (EM) stage is more important for orientation of the spacecraft. This will be achieved by using engine gimbal control (EGC) system.

The block diagram of the EM EGC system is shown in Fig. (1). The linear electromechanical actuators are mounted orthogonally for pitch and yaw axis control. The drive bar of the actuator is rigidly connected to the nut of the ball-screw and is attached to the engine with a gimbal. A Brushless DC torque motor which is powered by external battery supply is the driving element of the actuator. The motor is driven by pulse width modulator power amplifier. A high gain analog current loop around the PWM power amplifier with a bandwidth of the order of few $\mathrm{KHz}$ is used to ensure the linear power amplifier characteristics. A dual redundant linear variable differential transformer is used for sensing the actuator position. The output of the position sensor is the feedback to the controller which provides adequate relative stability and robustness to the system [7].

The rest of the paper is arranged as follows: In section 3, a mathematical model of the EM EGC system is done. In section 4, PID controller, LQR theory and hybrid Fuzzy-PID controller are designed and simulated. The results and the discussion on the results are shown in section 5. And the concluding work of the paper is presented in section 6 .

\section{EM EGC SYSTEM MODEL}

\subsection{BLDC Torque Motor Current Loop}

The torque motor current is determined by the PWM power amplifier characteristics and current loop dynamics. The torque motor coil current is (1),

$i_{m c}=V_{i} K_{A}$

Power amplifier remains in the linear zone as long as,

$\left|R_{m} i_{m c}+K_{b} \omega_{m}\right|<V_{s}$
Where, $V_{i}, K_{A}, R_{m}, K_{b}, \omega_{m}$ and $V_{s}$ denote power amplifier input voltage, power amplifier gain which is the inverse of current loop sensor gain, DC torque motor coil resistance per channel, motor back EMF constant, angular velocity of motor and voltage applied across the coil. Once the above condition is violated, the power amplifier gets saturated and the current loop effectively gets opened. Under this condition the coil current is,

$i_{m c}=\left(V_{s} \operatorname{sign}\left(V_{i}\right)-K_{b} \omega_{m}\right) / R_{m}$

The motor coil inductance is neglected as the coil time constant is relatively small. Let $N_{c h}$ is the number of channels. Then the total motor current is,

$i_{m}=i_{m c} N_{c h}$

\subsection{Rocket Model}

The mechanical portion of the EM EGC system is the rocket engine. The rocket is an object that has a wide range of dynamic motion. The model of the rocket engine can be obtained by using moment of inertia, rotational friction coefficient and stiffness. The transfer function of the rocket engine is derived as (5),

$G(S)=\frac{1}{526 s^{2}+1000 s+100}$

\subsection{Electro Mechanical Actuator}

The electrical portion of the EM EGC system is an electromechanical actuator. It is the driving element of the rocket which is the combination of brushless direct current motor and ball screw [8]. Brushless direct current motors have been proven to be the best $[9,10]$ in all around type of motors for aerospace applications.

The brushless DC motor is broken down into its essential dynamic elements such as inertia, back EMF and resistance. The load parameters such as moment of inertia, friction and stiffness are included in the load model. The driving amplifier is essentially an on-off switching network which is time modulated at the PWM frequency. The pulse width modulation block includes the appropriate non-linear switching circuitry. For power and heat considerations it is desirable to limit the voltage to the motor and thus voltage limiting is included. The simulink model for BLDC motor is shown in 


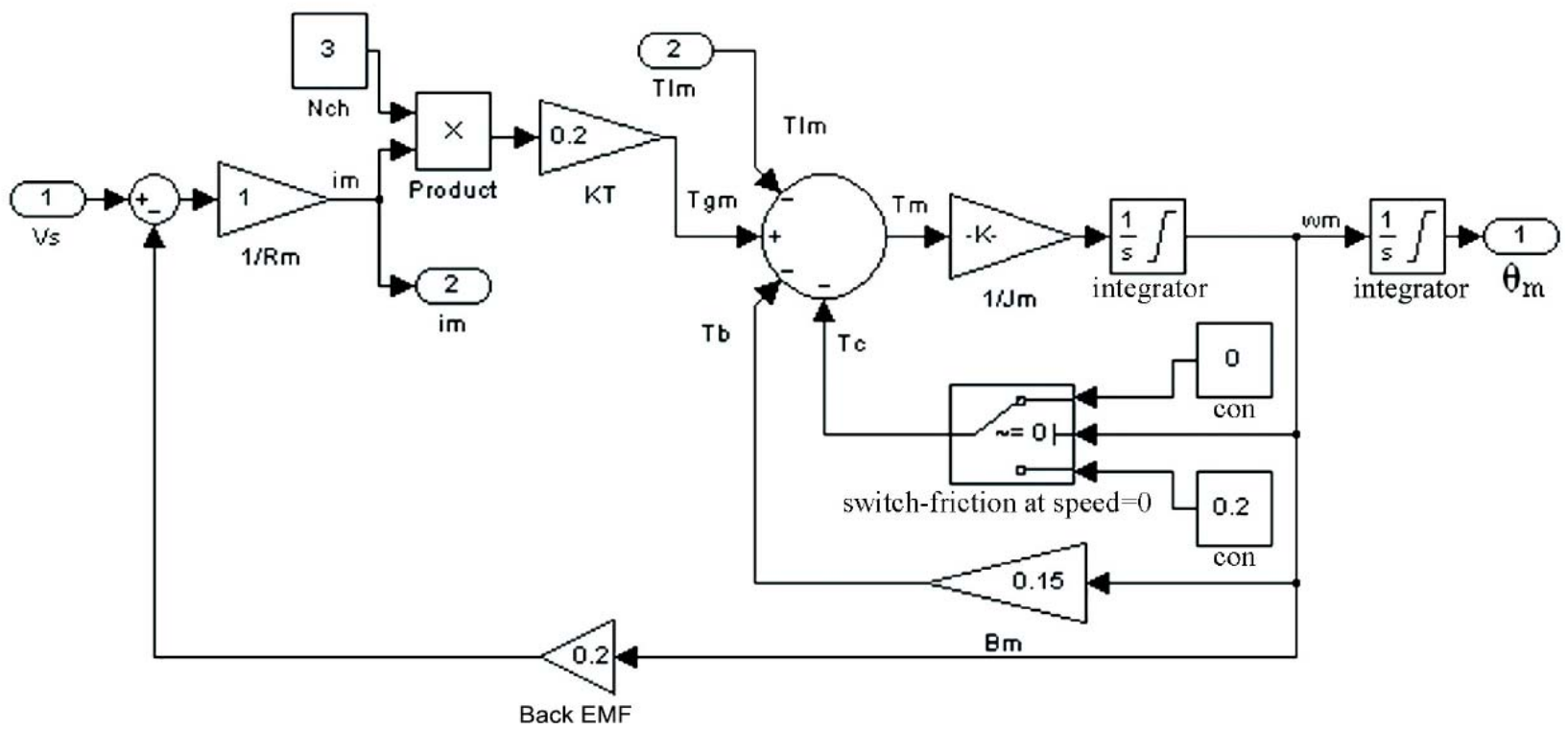

Fig. (2). Simulink Model of BLDC Motor.

Table 1. Model Specifications.

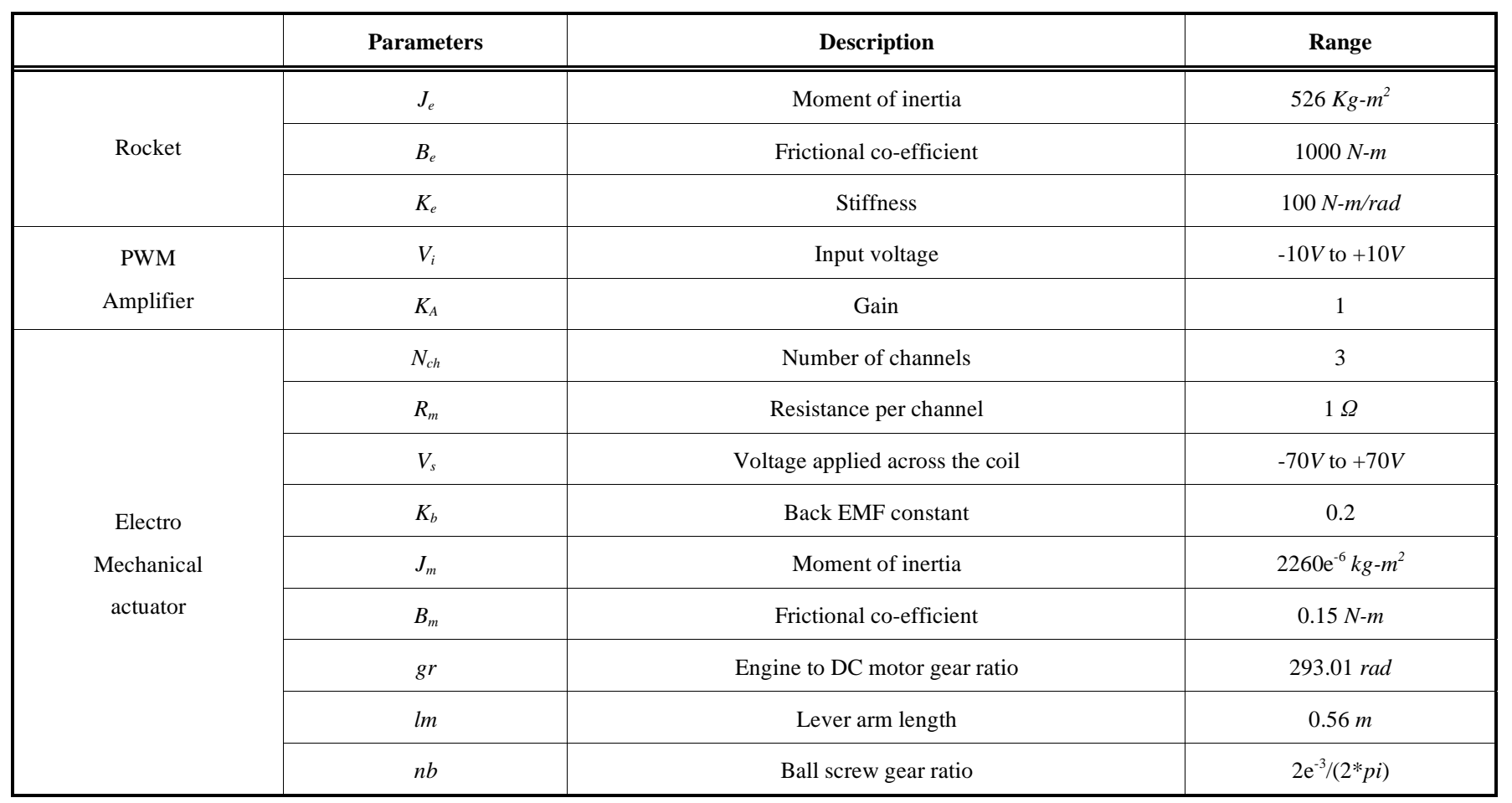

Fig. (2) and the specifications used in the simulation are given in Table $\mathbf{1}$.

\subsection{MATLAB Simulink Model}

The Matlab/Simulink model without any controller is developed for analysis. The response for the rocket nozzle gimbal angle of +3 degree is obtained. The open loop rocket model and the response are presented in Fig. (3) and Fig. (4) respectively. From the response, it is observed that there is no control in the gimbal angle. So, it is necessary to design an intelligent control system for the attitude control.

\section{DESIGN OF CONTROLLERS}

\subsection{PID Controller}

The majority of feedback control applications use PID controller [11]. This is because the implementation of PID controller is fairly easy to understand, build and tune. But a common problem occurred in PID control is noise produced by any real sensor which gives the measurement of the output shaft position. In rocket gimbal control system, the actuator position sensor is LVDT that produces a high frequency noise which implies that it has high values of 


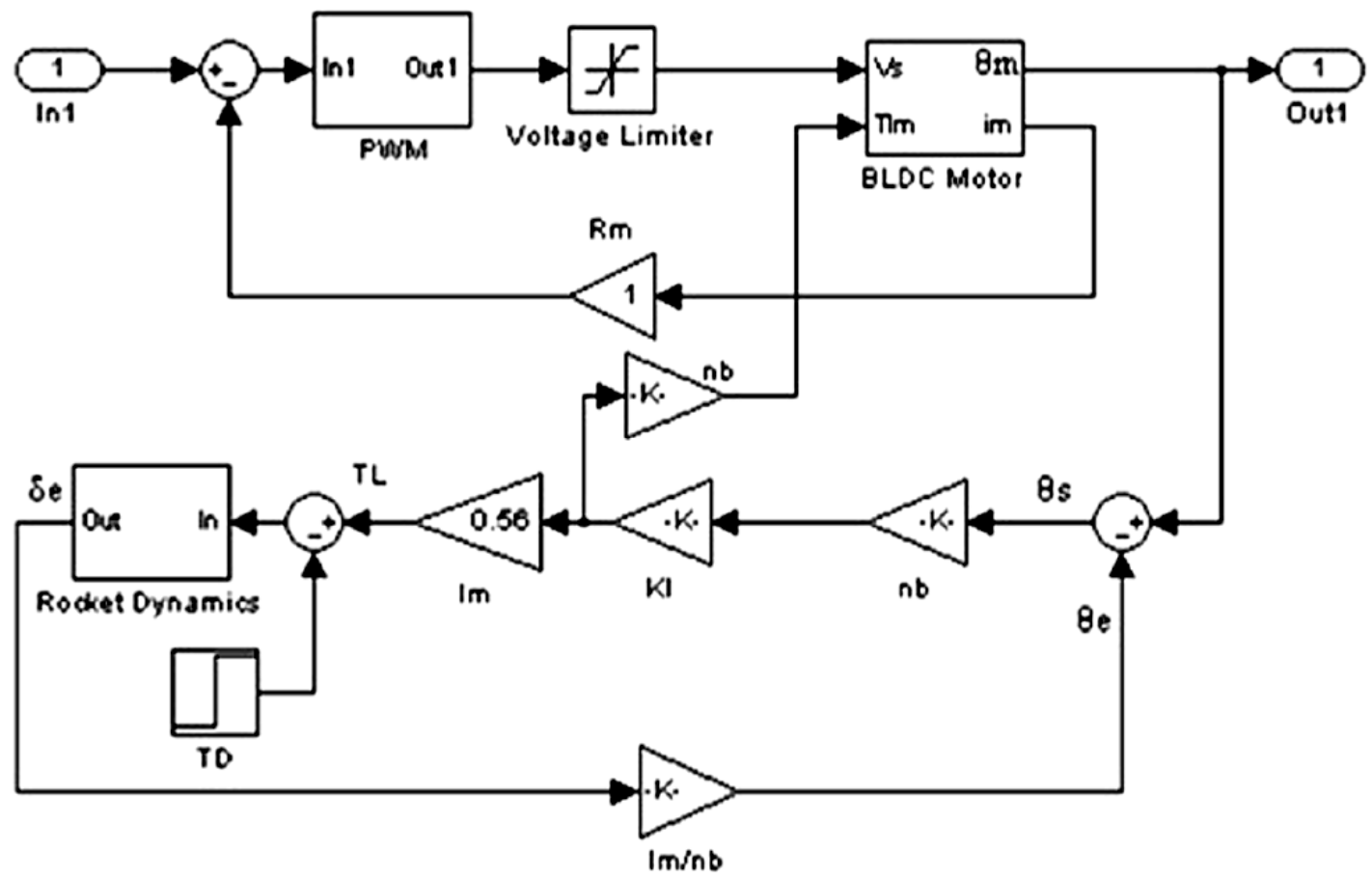

Fig. (3). Open loop Electro Mechanical Actuator System.

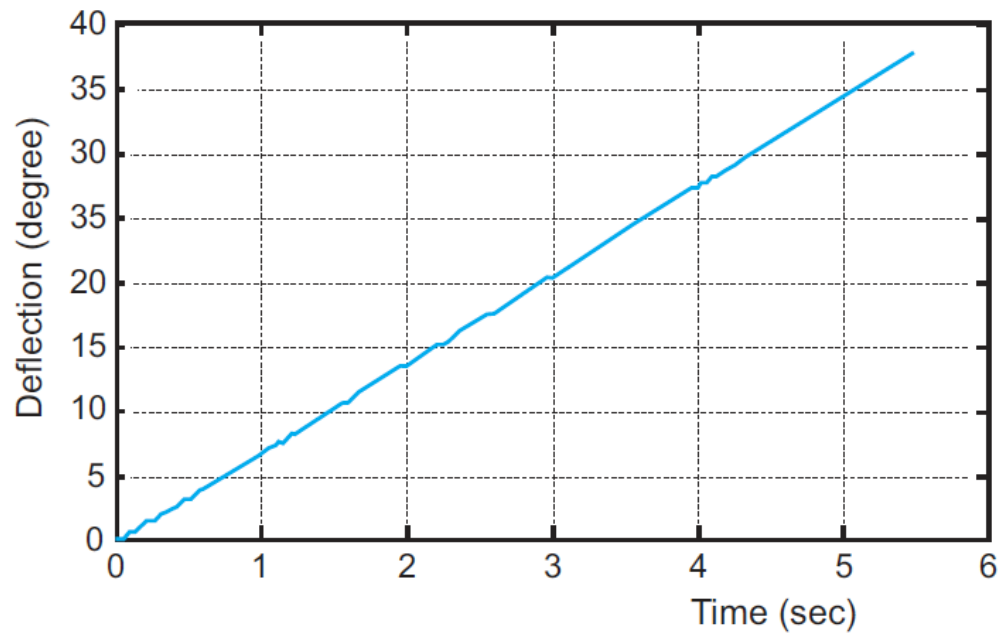

Fig. (4). Open loop Response for Deflection of $+3^{\circ}$

derivatives of that noise. This results too large input to the plant. To elude this problem, a first order low pass filter is placed on the derivative term and its pole is tuned. Since it attenuates high frequency noise, the chattering due to the noise does not occur. The final modified derivative term is,

$$
G_{m d}(s)=\frac{K_{d} s}{\frac{T_{d}}{N} s+1}
$$

Where, $K d, T d$ and $N$ denote derivative gain, derivative time and derivative filter constant respectively.

Here another problem arises in PID control is integral windup due to the presence of actuator limitations and nonlinear effect of the rocket. The actuator saturation occurs due to the input voltage applied to the PWM amplifier which is in the range of +10 to -10 volts. This actuator saturation effect is emphasized by limiting the control signal to +5 to -5 volts. This is achieved by placing a saturation block at the output of the PID controller. By incorporating an antiwindup scheme into the controller, the effect of integrator windup is minimized to obtain a faster rise time with less overshoot. The extra feedback loop reduces the input to the integrator in proportion to the saturation error [12]. The time constant $T t$ determines the speed with which the integral term is reset. It is chosen as $T t \leq T i$, where $T i$ is integral time of the controller [13].

By nesting PID controller using anti-windup mechanism with rocket gimbal control system, full control and robust requirements are achieved. The closed loop control system with a unity negative feedback is shown in Fig. (5). The controller parameters are all squared up using trial and error 


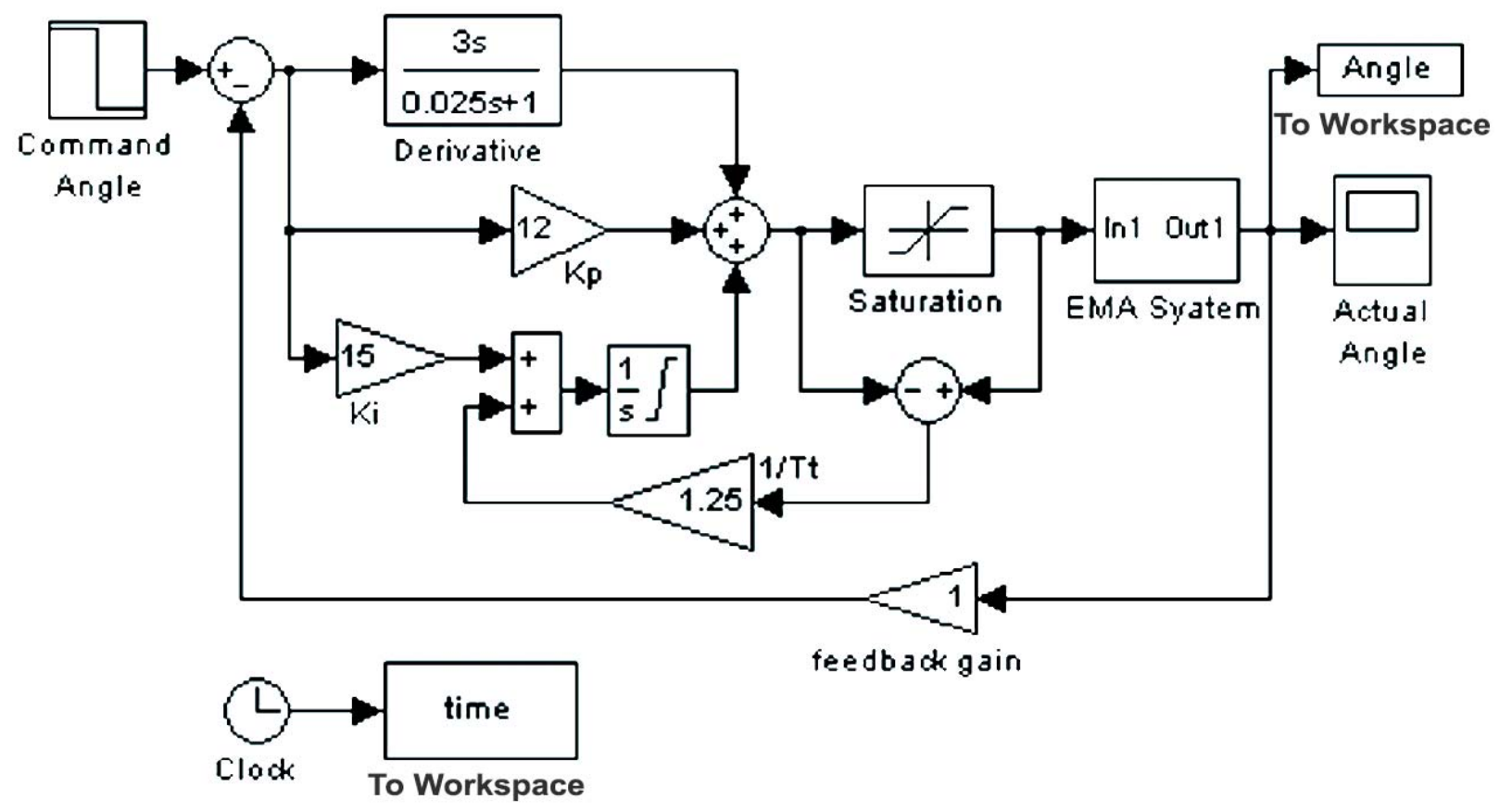

Fig. (5). Gimbal angle control by PID Controller with anti-windup scheme.

method. After several trial and error runs, the nominal values of the PID controller parameters are set as $K p=12, K i=15$, $K d=3, T d=0.25, T t=0.8$ and $N=10$ to provide the desired response.

Here, the difficulty lies in controlling parameter of the rocket. While the rocket is in flight, the controlling parameters of the model change with the different flying states but the three parameters of PID controller are constants. Therefore, the system has a bad adaptability. Also, the PID controller is more effective for linear systems. Since the rocket system is nonlinear, PID controller limits the performances. The drawbacks faced here is that the settling time is too high. Also it produces more overshoot and error.

\subsection{Linear Quadratic Regulator}

The optimal linear quadratic regulator method is a powerful technique for designing controllers for complex systems $[14,15]$. Here, the challenge lies in how the weighting matrices are chosen.

For the rocket engine gimbal control, an optimal displacement feedback control law is derived. Analytical expressions of the linear quadratic regulator feedback gains can be derived by using MATLAB command. The LQR design and analysis involve linearizing the nonlinear equations which describe the plant behavior and developing the state space model. The state space model together with an optimality criterion is used to control the engine gimbal angle.

\subsubsection{Model Development and Analysis}

For state space representation, the given nonlinear equations are presented in the state diagram with suitable blocks which are shown in Fig. (2). From this state diagram, by invoking the MATLAB command $\left[\begin{array}{llll}A & B & C & D\end{array}\right]=$ linmod ('filename'), the state space model of the given system is determined. By using MATLAB commands, the taken system is tested whether it is completely controllable, observable and stable. It gives an optimistic result which means the EM EGC system is eligible for arbitrary pole placement [16].

\subsubsection{LQR Control Law Development}

The LQR development involves finding the optimal control law $u(t)$. The design parameters have been chosen as,

$Q=\left[\begin{array}{lllll}1 & 0 & 0 & 0 & 0 \\ 0 & 1 & 0 & 0 & 0 \\ 0 & 0 & 1 & 0 & 0 \\ 0 & 0 & 0 & 1 & 0 \\ 0 & 0 & 0 & 0 & 1\end{array}\right]$

$R=1$

Where $\mathrm{Q}$ is positive semi-definite matrix and $\mathrm{R}$ is strictly positive scalar. In MATLAB, $[K p E]=\operatorname{lqr}(A, B, Q, R)$ command calculates the optimal feedback gain matrix ' $K$ ' such that the feedback control law minimizes the performance index. The LQR controller simulink model developed based on the above design is shown in Fig. (6) and Fig. (7). In designing LQR, the control law $u(t)$ and the matrices are selected as,

$$
\begin{aligned}
& u(t)=[0 K 2 K 3 K 4 K 5] x+K 1(r-x) \\
& A A=\mathrm{A}-B * K \\
& B B=B * K 1 \\
& C C=\mathrm{C}-D * K \\
& D D=D * K 1
\end{aligned}
$$




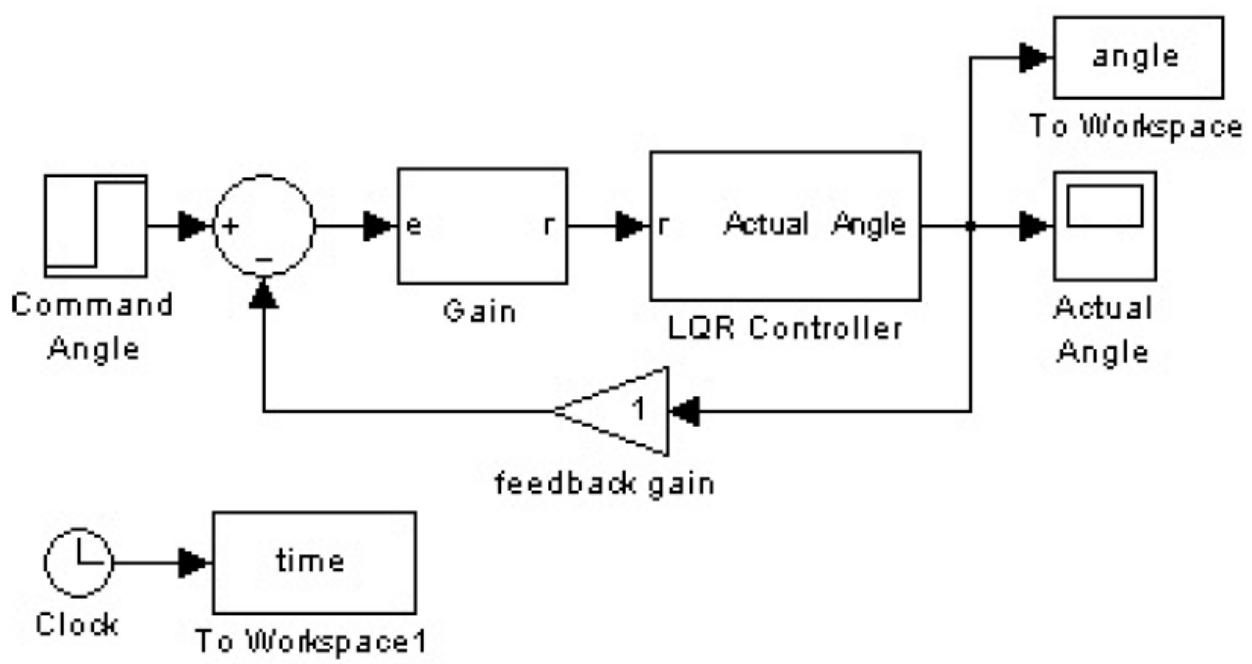

Fig. (6). Gimbal angle control by LQR.

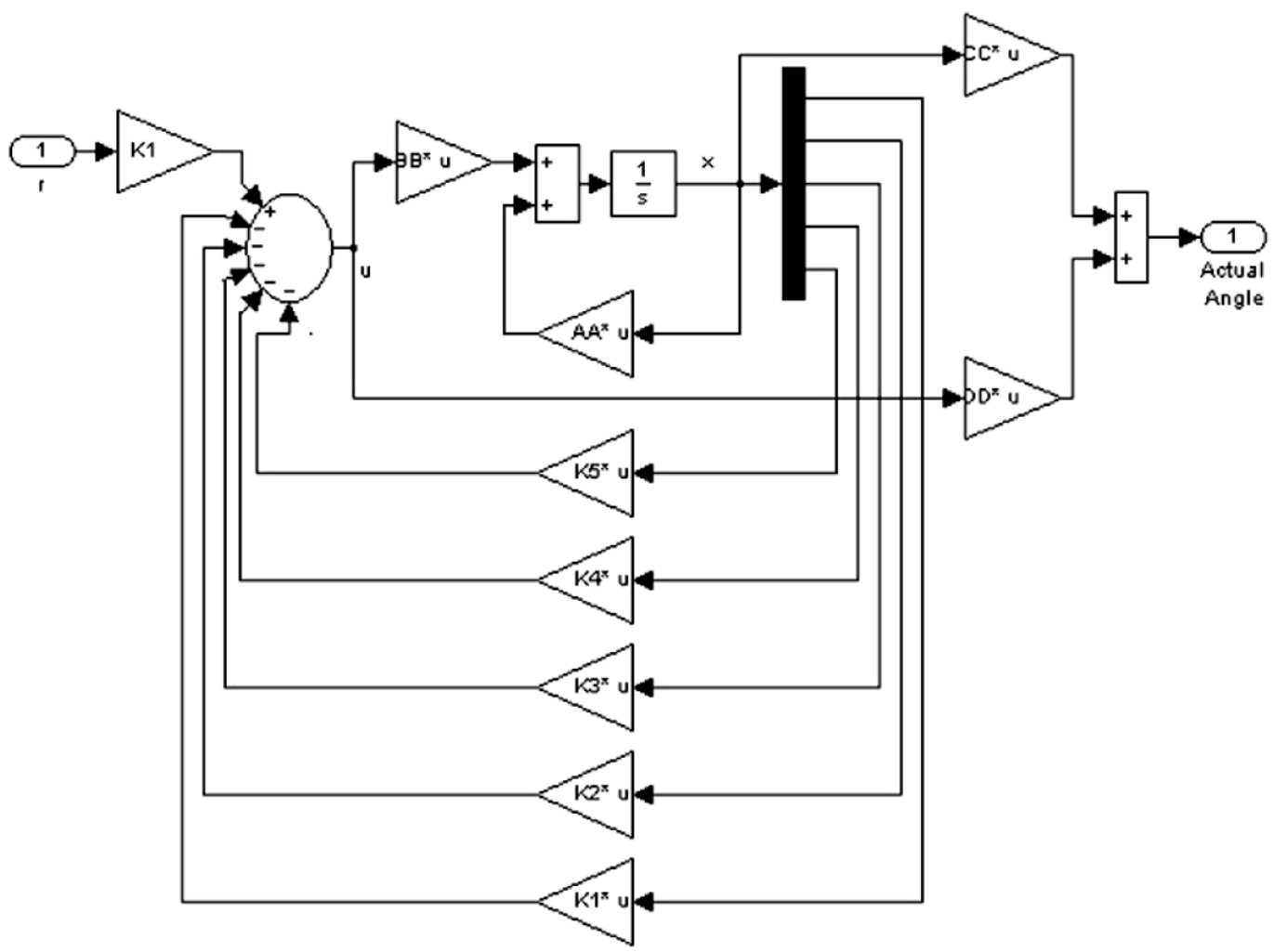

Fig. (7). Linear Quadratic Regulator.

Here, the designing methodology is complex and choosing the weighted matrix, control law is difficult. But comparing to PID controller, it's settling time is low and produces less overshoot. Since it produces an oscillatory response at the initial time, the rocket will not be stable for sometime. So, it is necessary to design an effective controller for this sensitive application.

\subsection{Fuzzy-PID Controller}

Fuzzy controllers are known for absorbing the nonlinearities of the system and work well for the real system. They are very powerful techniques in the field of system control, especially when the systems have large uncertainties and strong non-linearities. Also the fuzzy controller does not rely on the precise mathematical model of the controlled object. It approximates the plant's unknown dynamics [17]. PID controllers are often incorporated into the programmable logic controllers (PLCs) that are used to control many industrial processes. Unfortunately, the PID loops that are incorporated in rocket control system are in continual need of monitoring and adjustment since they can easily become improperly tuned due to the rocket parameter variations and operating condition changes. There is a significant need to develop methods for the automatic tuning of PID controllers [18]. Hybridization of PID and fuzzy controller provides the beneficial sides of both categories. 
Table 2. Input/output Range of FLC.

\begin{tabular}{|c|c|c|}
\hline Parameter & $\begin{array}{c}\text { Positive Angle } \\
\text { Deflection }\end{array}$ & $\begin{array}{c}\text { Negative Angle } \\
\text { Deflection }\end{array}$ \\
\hline \hline Error & -8 to 8 & -8 to 8 \\
\hline Change in Error & -2 to 2 & -2 to 2 \\
\hline Output & -5.15 to 1 & -1 to 2 \\
\hline
\end{tabular}

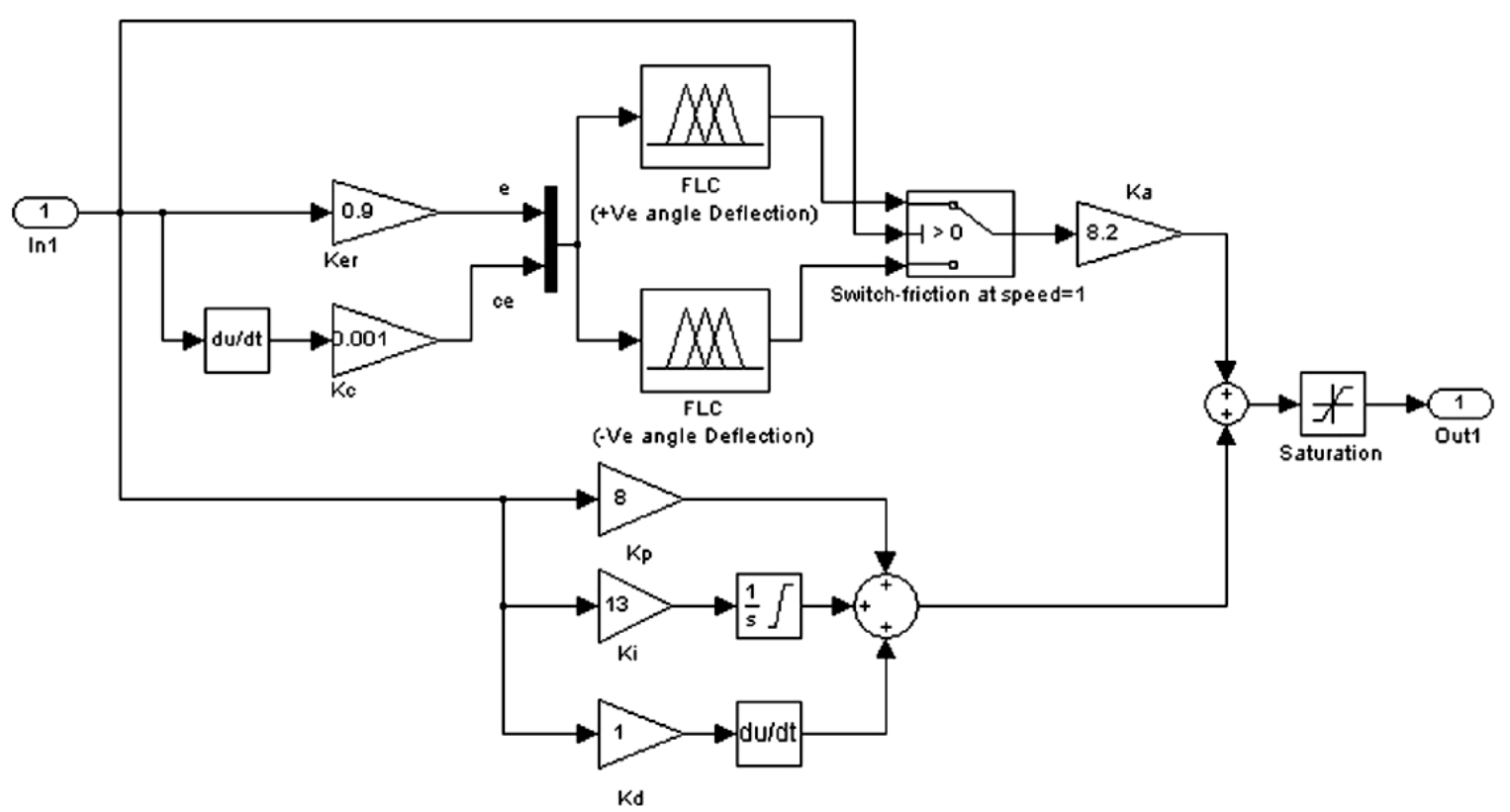

Fig. (8). Gimbal angle control by Hybrid Fuzzy-PID Controller.

The improved performances in both the transient and steady states have been achieved by the new hybrid fuzzyPID controller as compared to PID and LQR. It involves three main steps; Fuzzification, rule evaluation and defuzzification.

\subsubsection{Fuzzification}

The first step in designing a fuzzy logic controller is to decide state variables that represent the system dynamic performance. These state variables are taken as the input signal to the controller. For this, the triangular shaped membership function is the most economic one. The inputs are error $(e)$ in the angle deflection and corresponding change in error (ce). They are quantized into three fuzzy sets as negative $(N)$, zero $(Z)$ and positive $(P)$. The chosen ranges for the membership functions are shown in Table 2.

\subsubsection{Rule Base}

The controller output is determined by the following fuzzy rules:

If ( $e$ is positive) and (ce is positive)

then output is positive;

If ( $e$ is zero) and (ce is positive) then output is positive;

If ( $e$ is negative) and (ce is positive)

then output is zero;

If ( $e$ is positive) and (ce is zero)

then output is positive;

If ( $e$ is zero) and (ce is zero) then output is zero;

If ( $e$ is negative) and (ce is zero)

then output is negative;

If ( $e$ is positive) and (ce is negative)

then output is zero;

If ( $e$ is zero) and (ce is negative)

then output is negative;

If ( $e$ is negative) and (ce is negative)

then output is negative;

\subsubsection{Defuzzification}

The computing unit utilizes mamdani type fuzzy processing and the centre of area method to 'de-fuzzify' the results. The Matlab/Simulink model of the proposed fuzzy-PID based rocket control system is shown in Fig. (8). Here, two 


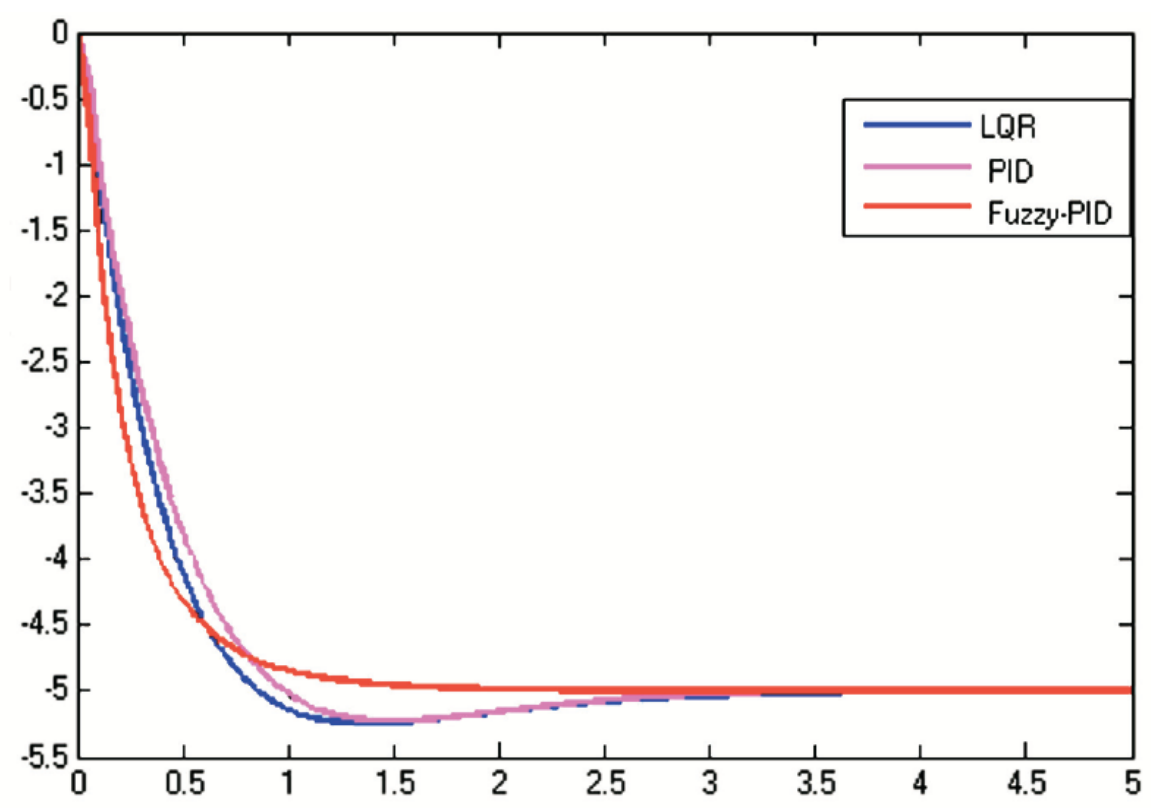

Fig. (9). Response for Deflection of $-5^{\circ}$.

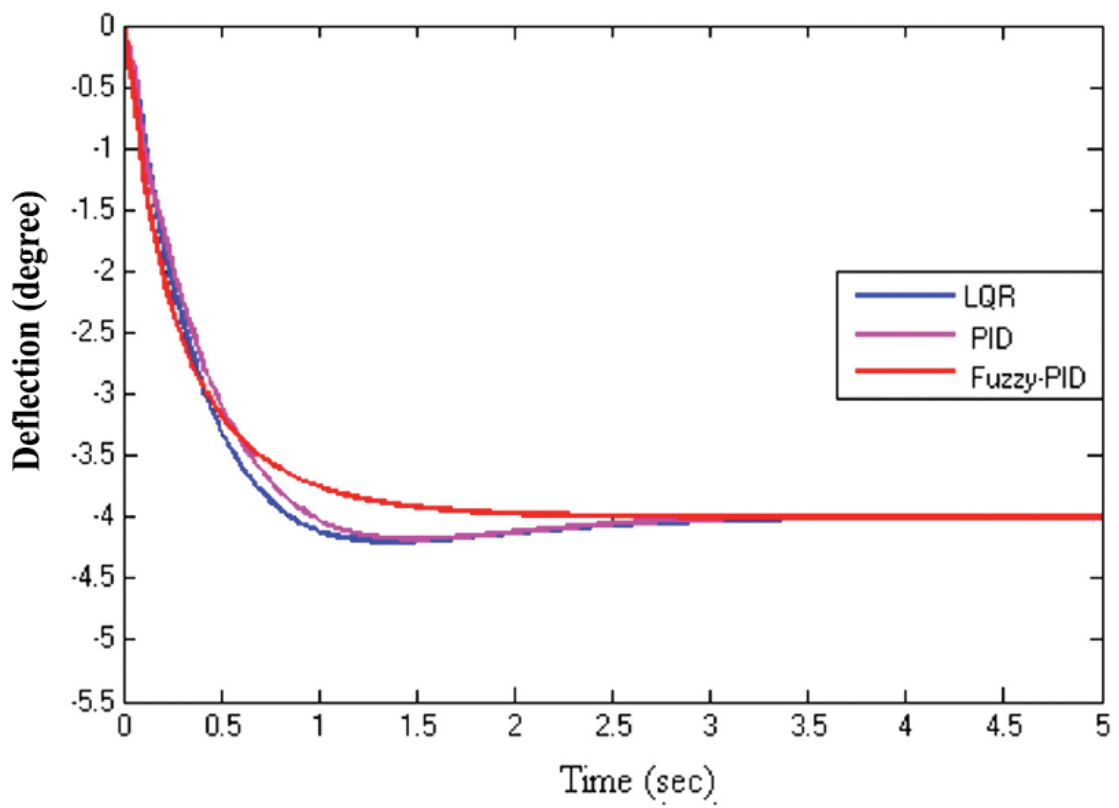

Fig. (10). Response for Deflection of $-4^{\circ}$.

fuzzy logic controllers are utilized to give better control performance. One is for positive angle deflection and another one is for negative angle deflection control. After numerous simulation experiments, the parameters of the fuzzy controller are selected as $K_{a}=0.6, K_{e r}=20$ and $K_{c}=0.2$. The PID controller parameters are chosen as $K_{p}=8, K_{i}=13$ and $K_{d}=1$.

\section{RESULTS AND DISCUSSION}

The simulations are carried out for various deflection angles in Matlab-simulink using the solver ODE45 to examine the performance of the proposed control system. The corresponding trajectories are illustrated in Fig. (9) to Fig. (14).
The value of time domain specifications such as settling time and peak overshoot are summarized in Table 3. The Integral Square Error (ISE) and Integral Absolute Error (IAE) are calculated and shown in Table 4. The most required quality of the controller is to have less overshoot, settling time and error. From the table, it is observed that the PID and LQR controllers have good static performance, while its response rate is not quick enough. The PID controller produce steady state error, overshoot in their response and settling time is high. In LQR, the rise time, settling time and steady state error is less compared to PID and produce more overshoot than PID. Still it is not a satisfied performance. 


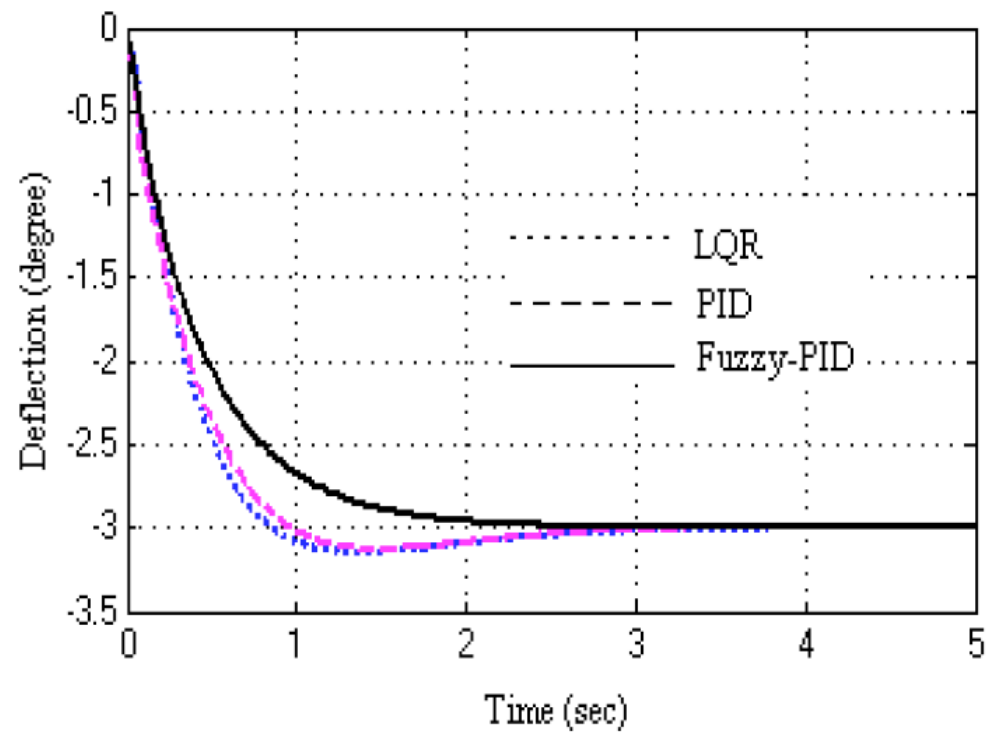

Fig. (11). Response for Deflection of $-3^{\circ}$.

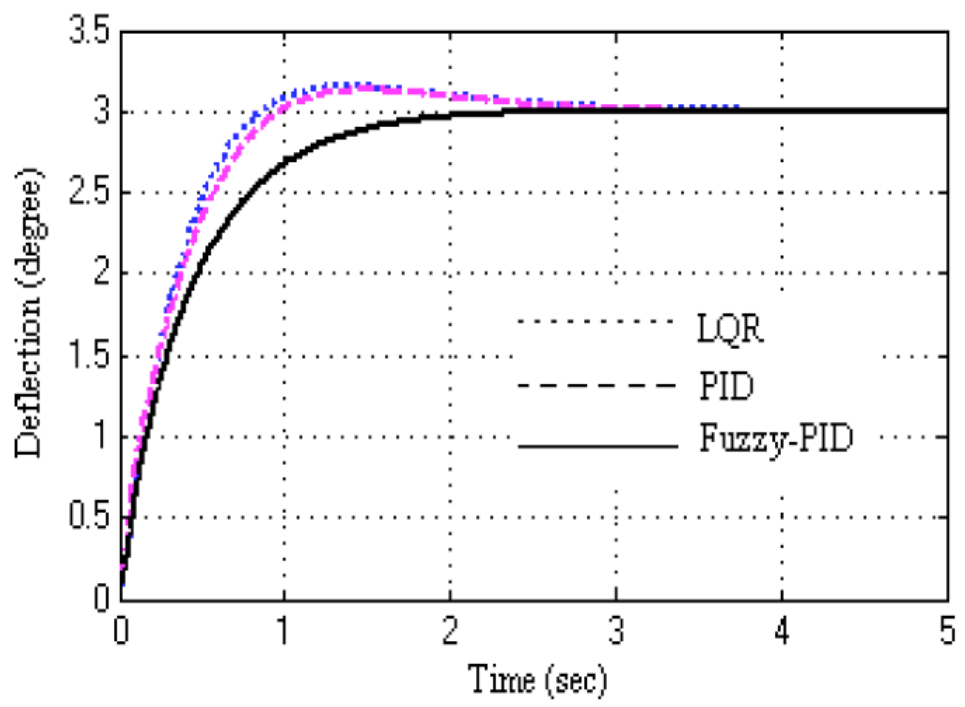

Fig. (12). Response for Deflection of $+3^{\circ}$.

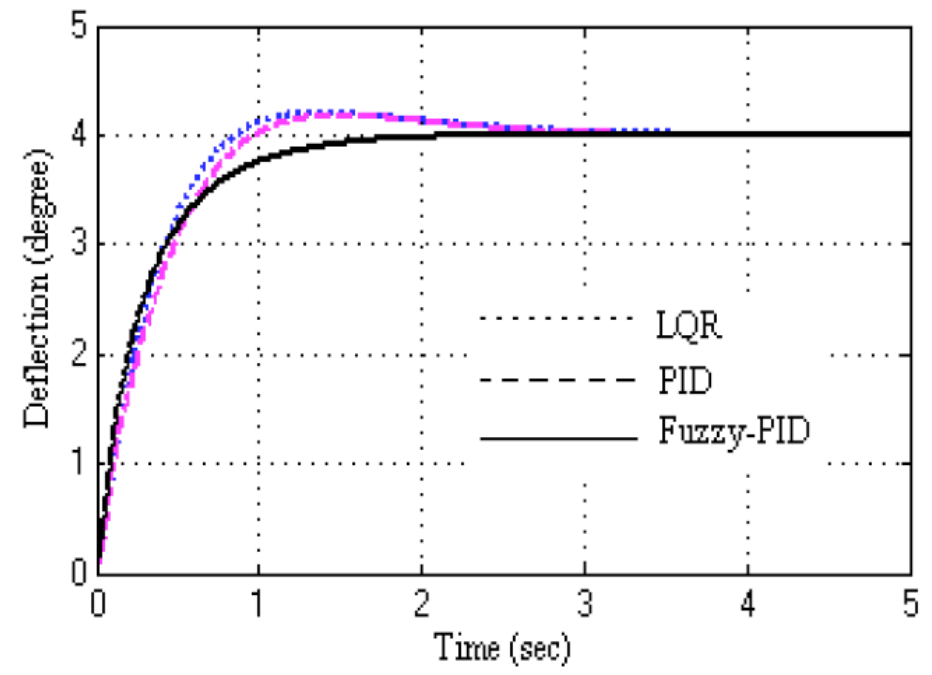

Fig. (13). Response for Deflection of $+4^{\circ}$. 


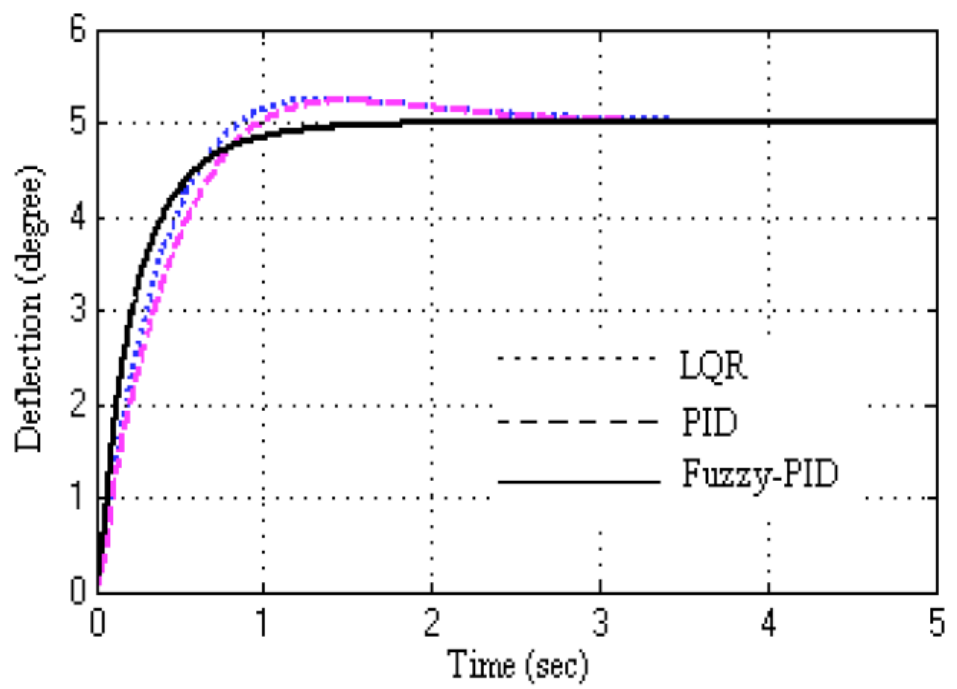

Fig. (14). Response for Deflection of $+5^{\circ}$.

Table 3. System characteristics.

\begin{tabular}{|c|c|c|c|c|c|c|}
\hline \multirow{2}{*}{$\begin{array}{c}\text { Set Point } \\
(\text { Degree) }\end{array}$} & \multicolumn{4}{|c|}{ Settling Time } & \multicolumn{2}{c|}{ Peak Overshoot } \\
\cline { 2 - 7 } & PID & LQR & Fuzzy-PID & PID & LQR & 5 \\
\hline \hline-5 & 9.4 & 10.6 & 3.1 & 4.62 & 5 & 0 \\
\hline-4 & 8.4 & 8.6 & 3 & 4.26 & 5 & 0 \\
\hline-3 & 7.6 & 7.8 & 2.9 & 4.26 & 5 & 0 \\
\hline 3 & 7.8 & 7.8 & 2.7 & 4.44 & 5 & 0 \\
\hline 4 & 8.3 & 8.6 & 2.5 & 4.58 & 5 & 0 \\
\hline
\end{tabular}

Table 4. Steady State Error comparison.

\begin{tabular}{|c|c|c|c|c|c|c|}
\hline \multirow{2}{*}{$\begin{array}{c}\text { Set point } \\
\text { (Degree) }\end{array}$} & \multicolumn{3}{|c|}{ ISE } & & \multicolumn{2}{c|}{ IAE } \\
\cline { 2 - 7 } & PID & LQR & Fuzzy-PID & PID & 1.925 & 1.773 \\
\hline \hline-5 & 4.917 & 4.331 & 3.238 & 1.484 & 1.418 & 1.322 \\
\hline-4 & 2.947 & 2.772 & 2.462 & 1.322 \\
\hline-3 & 1.516 & 1.559 & 1.943 & 1.059 & 1.064 & 1.322 \\
\hline 3 & 1.518 & 1.559 & 1.938 & 1.06 & 1.064 & 1.418 \\
\hline 4 & 2.949 & 2.772 & 2.46 & 1.485 & 1.312 \\
\hline 5 & 4.921 & 4.331 & 3.237 & 1.926 & 1.773 \\
\hline
\end{tabular}

The proposed fuzzy-PID controller is effectively eradicating these dangerous oscillations. Eventhough it has high rise time, it provides smooth operation in transient period and has less settling time. It produces zero overshoot and less steady state error that is unachievable with PID controller and LQR controller. Hence, it can be concluded that the proposed fuzzy-PID controller is more robust than the other controller.

\section{CONCLUSION}

The primary aim of this paper is to control the gimbal angle of rocket nozzle within a specified range and to make the rocket stable in flight. It has succeeded in the design of an intelligent hybrid fuzzy-PID controller. In this paper an improved PID controller using anti-windup scheme, LQR controller and hybrid fuzzy-PID controller are designed 
which can greatly improve the dynamic performances of the rocket control system. The Matlab/simulink model for electromechanical engine gimbal control system is developed with these three controllers.

Since the conventional PID controller is suitable for linear systems, the effects of non-linearities in the electromechanical actuator such as saturation and fiction could degrade the performance of conventional controllers. In the case of LQR controller designing, it requires more knowledge about the system and takes more time to design. Both PID and LQR controllers have high settling time and produce an oscillatory response resulting in the reduction of the stability of the rocket during the maneuver.

To conclude, the hybrid fuzzy-PID controller designed present is having more advantages with respect to the PID and LQR. Here it has less settling time and steady state error. As a result, the system exhibits a fast transient response with no overshoot. So, the proposed hybrid fuzzy-PID controller is a preferable choice for pitch and yaw attitude control of a rocket engine during electromechanical stage.

\section{CONFLICT OF INTEREST}

The authors confirm that this article content has no conflicts of interest.

\section{ACKNOWLEDGEMENTS}

The authors would like to thank Mr. Baby Sebastian, Scientist-Engineer-SF, Vikram Sarabhai Space Centre, Thiruvananthapuram, Kerala, India and Mr. M. Suresh Kumar, Scientist-Engineer-SE, ISRO Inertial System Unit, Thiruvananthapuram, Kerala, India for their suggestions and encouragement throughout the research.

\section{REFERENCES}

[1] B.K. Atmaja and E. Joelianto, "Surface Control Design of Rocket using MIMO PID Robust Integral Backstepping", 2nd International Conference on Instrumentation Control and Automation, pp. 162-169, Bandung, Indonesia, November 2011.

[2] M.M. Rashid and A. Wali, "Fuzzy-PID Hybrid Controller for Point-to-Point (PTP) Positioning System", American Journal of Scientific Research, Vol. 9, pp. 73-81, 2010.
[3] I. Erenoglu, I. Eksin, E. Yesil and M. Guzelkaya, "An Intelligent Hybrid Fuzzy PID Controller", Proceedings 20th European Conference on Modeling and Simulation, Wolfgang Borutzky, Alessandra Orsoni, Richard Zobel @ ECMS, 2006.

[4] D. Roy, R. Goswami, S. Sanyal and A.N. Sanyal, "Pitch Attitude Control of a Booster rocket", International Journal of Engineering and Science, vol. 2, pp. 8-12, 2013.

[5] Le Zhang, S. Bi and H. Yang, "Fuzzy-PID control algorithm of the helicopter model flight attitude control", Chinese Control and Decision Conference (CCDC), Chinese, pp. 1438 - 1443, May 2010.

[6] E.V. Narayana, V.S. Bonu and G.M. Rao, "PID Versus Fuzzy Logic Based Intelligent Controller Design for a Non Linear Satellite's Attitude Control: Performance Analysis using MATLAB/Simulink", International Journal of Advanced Engineering Sciences and Technologies, vol. 11, no. 1, pp.190-195, 2011.

[7] M.A. Davis, "High Performance Electromechanical Servo Actuation Using Brushless DC Motor", Moog Technical Bulletin 150, Motor-Con'84 Conference Proceedings, Atlantic City, April 1984.

[8] Hao Lu, Yunhua Li and Chenglin Zhu, "Robust synthesized control of electromechanical actuator for thrust vector system in spacecraft", Computers and Mathematics with Applications, vol. 64, pp. 699-708, 2012.

[9] R.P. Praveen et al., "Design and analysis of zero cogging brushless dc motor for spacecraft applications", ECTI Transactions on Electrical Engineering, Electronics and Communications, vol. 9, no. 1, pp. 113-120, 2011.

[10] United States, "Selection of Electric Motors for Aerospace Applications", Marshall Space Flight Center, Huntsville, USA, Practice No. PD-ED-1229, pp. 1-6, 1999.

[11] Farrukh Nagi, S.K. Ahmed, A.A. Zainul Abidin and F.H. Nordin, "Fuzzy bang-bang relay controller for satellite attitude control system", Fuzzy Sets and Systems, vol. 161, pp. 2104-2125, 2010.

[12] Srikanth Mandarapu, Sreedhar Lolla and M. V. Suresh Kumar, "Digital PI Controller using Anti-Wind-Up Mechanism for a Speed Controlled Electric Drive System", International Journal of Innovative Technology and Exploring Engineering, vol. 3, no. 1, pp. 239-242, June 2013.

[13] Staffan Haugwitz, Maria Karlsson, Stephane Velut and Per Hagander, "Anti-windup in mid-ranging control", Proceedings of the $44^{\text {th }}$ IEEE Conference on Decision and Control, and the European Control Conference 2005, pp. 12-15, 2005.

[14] Desineni Subbaram Naidu, “Optimal Control Systems", CRC Press, USA, 2009.

[15] J. Watkins and E.A. Mitchell, "MATLAB Graphical User Interface for Linear Quadratic Control Design", Frontiers in Education Conference, FIE 2000, pp. 7-10, 2000.

[16] Katsuhiko Ogata, "Modern Control Engineering", $3^{\text {rd }}$ ed, PrenticeHall of India Private limited, New Delhi, 1999.

[17] Wuxi Shi, Mu Zhang, Wencheng Guo and Lijin Guo, "Stable adaptive fuzzy control for MIMO nonlinear systems", Computers and Mathematics with Applications, vol. 62, pp. 2843-2853, 2011.

[18] Kevin M. Passino and Stephen Yurkovich, "Fuzzy Control", Addison Wesley Longman, Inc., California, 1998.

C Sumathi and Usha; Licensee Bentham Open.

This is an open access article licensed under the terms of the Creative Commons Attribution Non-Commercial License (http://creativecommons.org/licenses/by-nc/3.0/) which permits unrestricted, non-commercial use, distribution and reproduction in any medium, provided the work is properly cited. 